\title{
Efficacy and toxicity of docetaxel combination chemotherapy for advanced squamous cell cancer of the head and neck
}

\author{
ANDREAS E. ALBERS ${ }^{1 *}$, REGINA GRABOW $^{2 *}$, XU QIAN $^{1}$, MASEN D. JUMAH $^{3}$, \\ VEIT M. HOFMANN ${ }^{1}$, ALEXANDER KRANNICH ${ }^{4}$ and GABRIELE PECHER ${ }^{2}$
}

\footnotetext{
${ }^{1}$ Department of Otorhinolaryngology-Head and Neck Surgery, Charité-Universitätsmedizin Berlin, CBF, D-12203 Berlin; ${ }^{2}$ Medical Clinic of Hematology, Oncology and Tumor Immunology, Charité-Universitätsmedizin Berlin, CCM, D-10117 Berlin;

${ }^{3}$ Clinic of Otorhinolaryngology-Head and Neck Surgery, Villingen-Schwenningen Hospital, D-78052 Villingen Schwenningen;

${ }^{4}$ Coordination Center for Clinical Trials, Charité-Universitätsmedizin Berlin, CVK, D-13353 Berlin, Germany
}

Received February 3, 2017; Accepted May 31, 2017

DOI: $10.3892 /$ mco.2017.1281

\begin{abstract}
The aim of the present study was to evaluate the clinical effectiveness and toxicity of docetaxel with 5-fluorouracil and cisplatin as combination treatment in patients with curable or metastatic/recurrent head and neck cancer by a retrospective cohort study of patients treated at a single institution between 2007 and 2012. Patients with locally advanced, metastatic and/or recurrent squamous cell carcinoma of the head and neck (SCCHN), who were treated with a combination therapy including docetaxel, were considered as eligible. Survival data, clinical side effects, quality of life (QoL) and toxicity profile were retrieved from patient charts, analyzed and scored according to the National Cancer Institute Common Toxicity Criteria, version 4, and the Response Evaluation Criteria In Solid Tumors, version 1.1. An overall response rate of $86 \%$ and a 3-year survival of $65.1 \%$ were observed. The median progression-free survival was 32 months. The cumulative incidence after 3 years was $16.9 \%$ for local recurrence and $10.4 \%$ for distant metastasis. Leukopenia (58\%) and anemia (51\%) were the most common hematological toxicities, followed by hepatotoxicity $(53 \%)$ and nausea (27\%). A total of $31 \%$ of the patients experienced a compromise in their QoL following therapy completion. In conclusion, docetaxel in combination with cisplatin and 5-fluorouracil was found to effectively prolong survival in patients with locally advanced and/or recurrent metastatic SCCHN. The overall survival, progression-free survival and response rates were
\end{abstract}

Correspondence to: Dr Andreas E. Albers, Department of Otorhinolaryngology-Head and Neck Surgery, Charité-Universitätsmedizin Berlin, CBF, 30 Hindenburgdamm, D-12200 Berlin, Germany

E-mail: andreas.albers@charite.de

${ }^{*}$ Contributed equally

Key words: docetaxel, combination chemotherapy, head and neck cancer, incurable cancer, recurrent cancer, metastatic cancer in accordance with those reported by previous clinical trials. Therefore, this therapy protocol is recommended for patients with SCCHN in the curative as well as the palliative settings.

\section{Introduction}

Head and neck cancer is mostly of squamous cell origin (squamous cell carcinoma of the head and neck; SCCHN) and is the 10th most common type of cancer, with $>630,000$ cases diagnosed annually (1). Over 350,000 deaths from head and neck cancer were estimated to have occurred in 2008 worldwide (2). The frequency, incidence rates and locations of SCCHN vary widely among countries and continents (2-4).

Following the introduction of the TAX 323 and 324 studies, induction chemotherapy drew significant scientific and clinical interest, leading to further investigations $(3,5,6)$. The use of docetaxel in the treatment regimen was evaluated in those studies. Docetaxel promotes tubulin polymerization and affects the formation of stable microtubules, which leads to cell death (7). Recent results from multicenter studies and a current meta-analysis demonstrated that the combination of docetaxel with 5-fluorouracil (5-FU) and cisplatin (TPF regimen) is more efficacious compared with the classic regimen of cisplatin plus 5-FU ( $\mathrm{PF}$ regimen) as induction chemotherapy for advanced head and neck cancer (8). The TPF regimen achieved longer progression-free survival, better locoregional control and higher response rates $(9,10)$. An explanation for this advantage may be a better control of local and metastatic disease. Another aspect is the possibility of functional organ preservation when primary radiochemotherapy is used. Such approaches appear to be promising and are likely to improve the quality of life (QoL) of the patients, provided that survival is comparable to that with classic treatments and the side effects are manageable. Thus far, only a limited number of studies have investigated the effect of the organ-preserving TPF regimen on the QoL of SCCHN patients.

Radiochemotherapy is currently the cornerstone of treatment for SCCHN $(11,12)$, either alone or combined with surgery. However, a major disadvantage of induction chemotherapy is severe treatment-induced toxicity. TPF treatment was associated with a high percentage of patients experiencing 
myelosuppression, with grade 3 or 4 neutropenia $(5,6,13,14)$, as recently reported by a meta-analysis (8). The high incidence of toxicity may be the cause for the limited use of this combination treatment in the palliative setting. Moreover, the PARADIGM study that compared the addition of induction chemotherapy to radiochemotherapy vs. radiochemotherapy alone did not report an improvement in survival with induction chemotherapy prior to radiochemotherapy (15).

There are several different therapy schedules for the treatment of SCCHN, but a definitive therapeutic strategy has not yet been established. Promising results were obtained from only a few studies in which docetaxel was used as part of induction chemotherapy. Therefore, the clinical effectiveness and toxicity profile of docetaxel in combination with 5-FU and cisplatin was evaluated in a defined setting in patients with curable and metastatic/recurrent SCCHN in our hospital.

\section{Patients and methods}

Patient population. The medical records of patients with pathologically confirmed SCCHN, who received treatment with docetaxel at the hospitals of Charité-Universitätsmedizin Berlin, Germany, between April 2007 and May 2012, were retrospectively reviewed. Data were retrieved from the archives of Charité or from the attending physicians.

Treatment plan. The established treatment schedule consisted of an intravenous infusion of docetaxel at a dose of $75 \mathrm{mg} / \mathrm{m}^{2}$ followed by an intravenous infusion of cisplatin at $75 \mathrm{mg} / \mathrm{m}^{2}$ and a continuous 5-day infusion of 5-FU at a dose of $750 \mathrm{mg} / \mathrm{m}^{2}$. The cycles were repeated after 21 days. The treatment regimen was adapted when severe side effects occurred. In case of reduced kidney function, cisplatin was substituted by carboplatin.

Premedication with dexamethasone was administered in the evening of the day prior to the first TPF application. One hour prior to the initiation of therapy, antiemetic medication and mannitol with $0.9 \%$ saline solution were administered to prevent acute renal failure. As an additional preventive measure for agranulocytosis, granulocyte colony-stimulating factor (GCSF) was administered on day 6 to accelerate the recovery of therapy-induced neutropenia.

TPF induction chemotherapy was most frequently followed by targeted therapy with an anti-epidermal growth factor receptor antibody (cetuximab; loading dose of $400 \mathrm{mg} / \mathrm{m}^{2}$ with $250 \mathrm{mg} / \mathrm{m}^{2}$ over the subsequent weeks) with simultaneous intensity-modulated fractionated radiotherapy with a total dose of 54-79.2 Gy over 7 weeks, 5 days per week.

Clinical examination. To assess the disease status prior to and following therapy, the clinical evaluation routinely included panendoscopy and radiological evaluation consisting of computed tomography (CT) scans, abdominal sonography and additional magnetic resonance imaging and positron emission tomography/CT, or bone scintigraphy, as necessary. With this information, the decision on treatment strategy was made by an interdisciplinary tumor board consisting of oncologists, otolaryngologists and head and neck surgeons, maxillofacial surgeons, radiotherapists and pathologists.
The Karnofsky scale was used in this study in addition to chronic ailments, such as pain, ototoxicity, neurotoxicity, permanent tracheostoma or percutaneous endoscopic gastrostomy, to assess patient status.

Toxicity. The toxicity profile was divided into hematological and non-hematological events and was scored according to version 4 of the National Cancer Institute Common Terminology Criteria for Adverse Events (http://evs.nci.nih. gov/ftp1/CTCAE/CTCAE_4.03_2010-06-14_QuickReference_5x7. pdf).

Treatment outcome. The response rate (RR), overall survival (OS), progression-free survival (PFS), cumulative incidence of distant disease and locoregional control, toxicity, side effects and QoL were analyzed. The response to therapy was assessed according to the definitions of the Response Evaluation Criteria In Solid Tumors, version 1.1, published by the European Organization for Research and Treatment of Cancer (EORTC) $(12,16)$, National Cancer Institute of the United States, and the National Cancer Institute of Canada Clinical Trials Group: Complete response (CR) was defined as the disappearance of all signs of the current disease recorded from the start of the treatment. Partial response (PR) was defined as a decrease in the size of the tumor of $\sim 30 \%$. Stable disease (SD) was defined as no disease progression or regression. Progressive disease (PD) was defined as an increase in the tumor size of $>20 \%$ during or after treatment. Finally, a mixed response was defined as decrease at one site and progression at a different site. Patients with a mixed response were not included in the calculation of overall response rate (ORR) (16).

ORR was calculated based on CR, PR and SD, until the first sign of recurrence or PD was objectively recorded. The time of response evaluation in this study was calculated from the first day of treatment with TPF until the first follow-up examination after treatment. The OS was defined from the beginning of the treatment until the last date of contact or death.

Statistical analysis. All survival parameters were calculated using SPSS software, version 23 (IBM Corp., Armonk, NY, USA).

\section{Results}

Patient population. According to the abovementioned criteria, 45 patients with a median age of 57 years were included in the present study. Of those patients, 35 received curative therapy (CT) and 10 received palliative therapy (PT). A total of 6 patients received a modified therapy schedule with curative intent with reduced/adapted dosage due to a worsening general condition or pre-existing comorbidities. Data from all patients were available for evaluation of toxicity and survival time. The majority of the patients (87\%) were male. The review from the patient' charts revealed that nearly $>50 \%$ had a history of chronic alcohol abuse. Nicotine use was reported in $>60 \%$ in all groups and a simultaneous use of both substances in $90 \%$ in the curative and $100 \%$ in the palliative group. Approximately $>50 \%$ of the SCCHNs were diagnosed at an advanced stage (T4) with metastases in the regional lymph nodes (N2). The patient characteristics are summarized in Table I. 
Table I. Patient characteristics according to the different therapy approaches.

\begin{tabular}{|c|c|c|c|c|}
\hline Characteristics & $\begin{array}{c}\text { CT } \\
(n=30)\end{array}$ & $\begin{array}{c}\text { PT } \\
(\mathrm{n}=9)\end{array}$ & $\begin{array}{l}C \operatorname{TrD} \\
(\mathrm{n}=6)\end{array}$ & $\begin{array}{c}\text { Total } \\
(n=45)\end{array}$ \\
\hline \multicolumn{5}{|l|}{ Gender, no. (\%) } \\
\hline Male & $26(87)$ & $7(78)$ & $6(100)$ & $39(87)$ \\
\hline Female & $4(13)$ & $2(22)$ & $0(0)$ & $6(13)$ \\
\hline \multicolumn{5}{|l|}{ Alcohol consumption, no. (\%) } \\
\hline Yes & $14(47)$ & $9(100)$ & $3(50)$ & $26(58)$ \\
\hline No & $16(53)$ & $0(0)$ & $3(50)$ & $19(42)$ \\
\hline Recovering alcoholic & $2(7)$ & $0(0)$ & $0(0)$ & $2(4)$ \\
\hline \multicolumn{5}{|l|}{ Nicotine consumption, no. (\%) } \\
\hline Yes & $27(90)$ & $9(100)$ & $4(67)$ & $40(89)$ \\
\hline Never smoker & $3(10)$ & $0(0)$ & $2(33)$ & $5(11)$ \\
\hline Former smoker & $7(23)$ & $0(0)$ & $0(0)$ & $7(16)$ \\
\hline Alcohol and nicotine consumption, no. (\%) & $14(47)$ & $9(100)$ & $2(33)$ & $25(56)$ \\
\hline \multicolumn{5}{|l|}{ Comorbidities, no. $(\%)$} \\
\hline Hypertension & $2(7)$ & $4(44)$ & $1(17)$ & $7(16)$ \\
\hline Diabetes mellitus & $3(10)$ & $1(11)$ & $1(17)$ & $5(11)$ \\
\hline Trauma & $5(17)$ & $2(22)$ & $0(17)$ & $7(16)$ \\
\hline Heart disease & $2(7)$ & $2(22)$ & $2(33)$ & $6(13)$ \\
\hline Previous malignancy & $5(17)$ & $0(0)$ & $1(17)$ & $6(13)$ \\
\hline \multicolumn{5}{|l|}{ Localization, no. (\%) } \\
\hline Epipharynx & $5(17)$ & $0(0)$ & $0(0)$ & $5(11)$ \\
\hline Oropharynx & $6(20)$ & $5(56)$ & $3(50)$ & $14(31)$ \\
\hline Hypopharynx & $4(13)$ & $1(11)$ & $1(17)$ & $6(13)$ \\
\hline Larynx & $9(30)$ & $0(0)$ & $0(0)$ & $9(20)$ \\
\hline Floor of mouth & $4(13)$ & $0(0)$ & $1(17)$ & $5(11)$ \\
\hline Tongue & $2(7)$ & $2(22)$ & $1(17)$ & $5(11)$ \\
\hline Other & $0(0)$ & $1(11)$ & $0(0)$ & $1(2)$ \\
\hline \multicolumn{5}{|l|}{ T classification, no. (\%) } \\
\hline $\mathrm{T} 1$ & $0(0)$ & $0(0)$ & $1(17)$ & $1(2)$ \\
\hline $\mathrm{T} 2$ & $4(13)$ & $2(22)$ & $1(17)$ & $7(16)$ \\
\hline $\mathrm{T} 3$ & $5(17)$ & $3(33)$ & $2(33)$ & $10(22)$ \\
\hline $\mathrm{T} 4$ & $21(70)$ & $3(33)$ & $2(33)$ & $26(58)$ \\
\hline $\mathrm{Tx}$ & $0(0)$ & $1(11)$ & $0(0)$ & $1(2)$ \\
\hline \multicolumn{5}{|l|}{$\mathrm{N}$ classification, no. (\%) } \\
\hline NO & $6(20)$ & $1(11)$ & $0(0)$ & $7(16)$ \\
\hline $\mathrm{N} 1$ & $1(3)$ & $0(0)$ & $0(0)$ & $1(2)$ \\
\hline $\mathrm{N} 2$ & $16(53)$ & $5(56)$ & $2(33)$ & $23(51)$ \\
\hline N3 & $6(20)$ & $2(22)$ & $4(67)$ & $12(27)$ \\
\hline $\mathrm{Nx}$ & $1(3)$ & $1(11)$ & $0(0)$ & $2(4)$ \\
\hline \multicolumn{5}{|l|}{ Recurrence prior to TPF therapy, no. (\%) } \\
\hline Yes & $0(0)$ & $5(56)$ & $0(0)$ & $5(11)$ \\
\hline No & $30(100)$ & $4(44)$ & $6(100)$ & $40(89)$ \\
\hline
\end{tabular}

CT, curative therapy; PT, palliative therapy; CTrD, therapy with curative intent with reduced/adapted dosage; TPF, docetaxel, 5-fluorouracil and cisplatin.

Patient status. The Karnofsky score was ranked as 60-100\% before and $0-100 \%$ after therapy. No information on general conditions was available in 10 patients. In 8 patients, the score decreased to $31 \%$ after treatment. Patients with an initial score of $<70 \%$ were at risk for further decrease, which was already visible during treatment. Patients treated with a palliative intent had lower scores during TPF treatment. The Karnofsky scores and chronic ailments are listed in Table II. 
Table II. Karnofsky score measured among patients in different groups before, during and after TPF therapy.

\begin{tabular}{|c|c|c|c|c|c|c|c|c|c|c|}
\hline \multirow[b]{3}{*}{ Type of treatment } & \multicolumn{10}{|c|}{ Karnofsky score (\%) } \\
\hline & \multicolumn{3}{|c|}{ Before treatment } & \multicolumn{3}{|c|}{ During treatment } & \multicolumn{3}{|c|}{ After treatment } & \multirow[b]{2}{*}{ Missing } \\
\hline & $\geq 90$ & $<90$ & $<50$ & $\geq 90$ & $<90$ & $<50$ & $\geq 90$ & $<90$ & $<50$ & \\
\hline $\mathrm{CT}$ & 23 & 3 & 0 & 17 & 9 & 0 & 22 & 4 & 0 & 4 \\
\hline PT & 2 & 4 & 0 & 2 & 2 & 2 & 2 & 1 & 3 & 3 \\
\hline CTrD & 2 & 1 & 0 & 2 & 0 & 1 & 2 & 0 & 1 & 3 \\
\hline Total & 27 & 8 & 0 & 21 & 11 & 3 & 26 & 5 & 4 & 10 \\
\hline
\end{tabular}

TPF, docetaxel, 5-fluorouracil and cisplatin; CT, curative therapy; PT, palliative therapy; $\mathrm{CTrD}$, therapy with curative intent with reduced/adapted dosage.

Table III. Treatment completion and subsequent therapy strategies.

\begin{tabular}{lcccc}
\hline Treatment & $\begin{array}{c}\mathrm{CT} \\
(\mathrm{n}=30)\end{array}$ & $\begin{array}{c}\text { PT } \\
(\mathrm{n}=9)\end{array}$ & $\begin{array}{c}\text { CTrD } \\
(\mathrm{n}=6)\end{array}$ & $\begin{array}{c}\text { Total } \\
(\mathrm{n}=45)\end{array}$ \\
\hline $\begin{array}{l}\text { Completed } \\
\text { treatment, no. (\%) }\end{array}$ & $26(87)$ & $4(44)$ & $5(83)$ & $35(77)$ \\
$\begin{array}{l}\text { Subsequent } \\
\text { treatment, no. (\%) }\end{array}$ & & & & \\
$\quad$ RT with cetuximab & $13(43)$ & $2(22)$ & $4(67)$ & $19(42)$ \\
CRT & $13(43)$ & $2(22)$ & $2(33)$ & $17(38)$ \\
RT & $2(7)$ & $2(22)$ & $0(0)$ & $7(16)$ \\
Resection & $1(3)$ & $0(0)$ & $0(0)$ & $1(2)$ \\
$\quad$ None possible & $1(3)$ & $3(33)$ & $0(0)$ & $1(2)$ \\
Reduced dosage, & $2(7)$ & $3(33)$ & $2(33)$ & $7(16)$ \\
no. $(\%)$ & & & & \\
\hline
\end{tabular}

RT, radiotherapy, CRT, chemoradiotherapy, CT, curative therapy; PT, palliative therapy; $\mathrm{CTrD}$, therapy with curative intent with reduced/adapted dosage.

Treatment characteristics. A total of $87 \%$ of the patients received chemotherapy based on the treatment schedule described in the methods section, and $80 \%$ of all patients completed the therapy. A total of 4 patients required a dose reduction after the first and second cycles due to severe mucositis, nephrotoxicity and ototoxicity. The most common reason for discontinuing treatment was a poor treatment response. To reduce the side effects, the treatment regimen was individualized in 6 patients, who received platinum agents other than cisplatin, such as carboplatin, oxaliplatin or lipoplatin, or by reducing the dosage of docetaxel to $50 \mathrm{mg} / \mathrm{m}^{2}$. By contrast, the dosage of 5-FU was increased to $1,000 \mathrm{mg} / \mathrm{m}^{2}$ from $750 \mathrm{mg} / \mathrm{m}^{2}$ (Table III).

Efficacy. An ORR of $86 \%$ was registered (93\% in the curative group, $75 \%$ in the palliative group and $67 \%$ in the modified regimen group). Over $50 \%$ of the patients treated with a curative intent reached a CR after completing chemotherapy and further treatment. The data on response to treatment are
Table IV. Response to treatment.

\begin{tabular}{lcccr}
\hline Variables & $\begin{array}{c}\mathrm{CT} \\
(\mathrm{n}=30)\end{array}$ & $\begin{array}{c}\text { PT } \\
(\mathrm{n}=9)\end{array}$ & $\begin{array}{r}\text { CTrD } \\
(\mathrm{n}=6)\end{array}$ & $\begin{array}{r}\text { Total } \\
(\mathrm{n}=45)\end{array}$ \\
\hline Response to TPF, \% & & & & \\
$\quad$ Overall response & 93 & 75 & 67 & 86 \\
Complete response & 10 & 0 & 17 & 9 \\
Partial response & 66 & 25 & 33 & 53 \\
Stable disease & 17 & 50 & 17 & 23 \\
Response to TPF and & & & & \\
subsequent therapy, \% & & & & \\
Overall response & 93 & 75 & 67 & 86 \\
Complete response & 51 & 25 & 33 & 44 \\
Partial response & 7 & 0 & 0 & 5 \\
Stable disease & 0 & 0 & 0 & 0 \\
\hline
\end{tabular}

TPF, docetaxel, 5-fluorouracil and cisplatin; CR, complete response; $\mathrm{PR}$, partial response; $\mathrm{SD}$, stable disease; CT, curative therapy; PT, palliative therapy; $C \operatorname{TrD}$, therapy with curative intent with reduced/adapted dosage.

summarized in Table IV. One patient treated with a palliative intent succumbed to the disease after the second cycle of TPF, due to the advanced stage and poor general condition.

Patients were followed up for a median of 44.9 months. The median OS was not reached, except for the palliative group, with a median OS of 9 months.

The estimated 1-year survival rate was $78.6 \%$, the 2 -year survival rate was $75 \%$ and the 3 -year survival rate was $65.1 \%$ for the entire patient population. In total, 12 patients $(27 \%)$ succumbed to the disease during follow-up. The median PFS was 32 months. Estimations of the PFS at 1 year were $63 \%$, at 2 years $57 \%$ and at 3 years $36 \%$. The cumulative incidence rate of locoregional failure at 1 year was $8 \%$. In total, distant metastases occurred retrospectively in 3 patients. The cumulative incidence rate of distant metastases at 1 year was $4 \%$. Kaplan-Meier curves showed better OS $(\mathrm{P}=0.03)$, Recurrence-free survival $(\mathrm{P}=0.001)$ and PFS $(\mathrm{P}=0.02)$ in the $\mathrm{CT}$ group compared with those in the PT group (Fig. 1). 
A

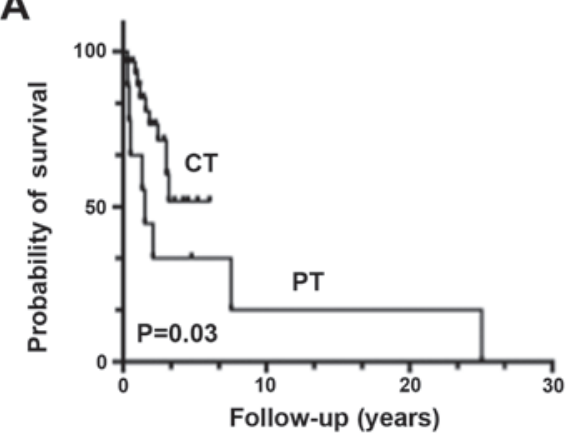

B

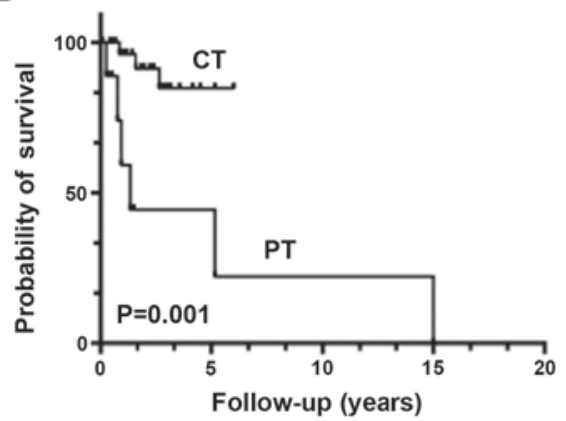

C

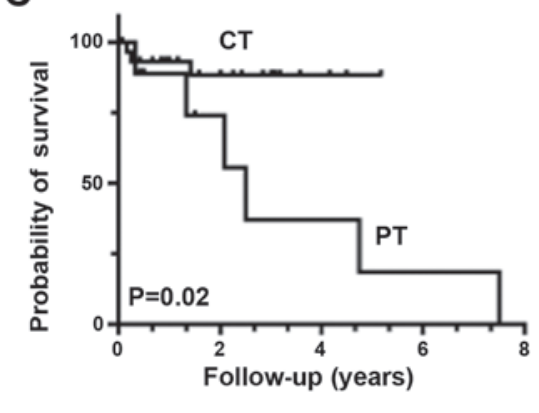

Figure 1. Kaplan-Meier curve for probability of (A) overall survival, (B) recurrence-free survival and (C) progression-free survival by curative therapy (CT) and palliative therapy (PT) in patients with squamous cell carcinoma of the head and neck.

Table V. Hematological and non-hematological adverse events during TPF therapy.

\begin{tabular}{lcc}
\hline Adverse events & Grade I-II & Grade III-IV \\
\hline Hematological, \% & 49 & 2 \\
Anaemia & 25 & 33 \\
Leukopenia & 11 & 22 \\
Lymphopenia & 0 & 13 \\
Neutropenia & 16 & 2 \\
Thrombopenia & & \\
Non-hematological, \% & 51 & 2 \\
Hypertransaminasemia & 24 & 2 \\
Hypercreatininaemia & 11 & 2 \\
Hypokaliaemia & 36 & 7 \\
Hyponatriaemia & 2 & 4 \\
Hypomagnesaemia & 13 & 0 \\
Hyperglycaemia & 2 & 2 \\
Hypocalcaemia & & \\
\hline
\end{tabular}

TPF, docetaxel, 5-fluorouracil and cisplatin.

Toxicity and side effects. Hematological toxicity was documented in all patients. The grade 3 and 4 adverse events were leukopenia and lymphopenia. The duration of the hematological toxic effects was relatively brief and they were alleviated after a median of 1 week. The low leukocyte count may be explained by the documented bacterial infections, which were treated with antibiotics. Additionally, an oropharyngeal infection with Candida albicans was diagnosed and treated with topical antimycotics.

Severe neutropenia was not very common $(13 \%)$ and was managed by human GCSF, which was part of the treatment schedule. Non-hematological toxicities occurred in $>50 \%$ of the study population. A total of $51 \%$ patients exhibited a small increase in liver enzyme levels, which was the most common toxicity in this category.

The most frequent side effects were gastrointestinal reactions, including nausea (27\%), emesis (13\%) and diarrhea (11\%). All adverse events were more severe in the patient cohort treated with a palliative intent and they are summarized in Tables V and VI.
Table VI. Side effects during TPF therapy.

\begin{tabular}{lcclc}
\hline & $\begin{array}{c}\mathrm{CT}, \\
\mathrm{n}(\%) \\
(\mathrm{n}=30)\end{array}$ & $\begin{array}{c}\mathrm{PT}, \\
\mathrm{n}(\%) \\
(\mathrm{n}=9)\end{array}$ & $\begin{array}{l}\mathrm{CTrD}, \\
\mathrm{n}(\%) \\
(\mathrm{n}=6)\end{array}$ & $\begin{array}{c}\text { Total, } \\
\mathrm{n}(\%) \\
(\mathrm{n}=45)\end{array}$ \\
\hline Side effects & $10(33)$ & $1(11)$ & $1(17)$ & $12(27)$ \\
Emesis & $4(13)$ & $1(11)$ & $1(17)$ & $6(13)$ \\
Diarrhea & $2(7)$ & $2(22)$ & $1(17)$ & $5(11)$ \\
Mucositis & $2(7)$ & $3(33)$ & $3(50)$ & $8(18)$ \\
Algesia & $3(10)$ & $3(33)$ & $2(33)$ & $8(18)$ \\
Fever & $6(20)$ & $1(11)$ & $1(17)$ & $8(18)$ \\
Infection & $3(10)$ & $2(22)$ & $0(0)$ & $5(11)$ \\
Ototoxicity & $2(7)$ & $0(0)$ & $0(0)$ & $2(4)$ \\
Neurotoxicity & $1(3)$ & $0(0)$ & $1(17)$ & $2(4)$ \\
Acute renal failure & $1(3)$ & $1(11)$ & $1(17)$ & $3(7)$ \\
Atrial fibrillation & $1(3)$ & $0(0)$ & $0(0)$ & $1(2)$ \\
Thrombosis & $2(7)$ & $1(11)$ & $0(0)$ & $3(7)$ \\
\hline
\end{tabular}

TPF, docetaxel, 5-fluorouracil and cisplatin; CT, curative therapy; PT, palliative therapy; $\mathrm{CTrD}$, therapy with curative intent with reduced/adapted dosage.

\section{Discussion}

Based on the observations and evaluations in this study cohort, it may be concluded that docetaxel applied in combination with cisplatin and 5-FU is an effective therapy for locally advanced, recurrent or metastatic SCCHN, in accordance with previous clinical trials.

SCCHNs are locally aggressive and may develop regional metastases. Induction chemotherapy with platinum-based agents and 5-FU has achieved improved results compared with the current classic therapies in terms of survival, locoregional disease control and organ function and, most importantly, in terms of swallowing function maintenance and voice preservation (17). In the TAX 323 trial, 358 patients with inoperable SCCHN were enrolled. The group treated with TPF $(n=177)$ experienced a significantly longer PFS of 11.0 months, compared with 8.2 months for patients treated with PF alone $(n=181)$, with an ORR of $68 \%$. At a median follow-up period of 51.1 months, patients receiving the docetaxel-based 
regimen achieved a median OS improvement of 4.3 months compared with those receiving standard chemotherapy with PF. Treatment with TPF resulted in a $27 \%$ reduction in the mortality risk. The incidence of grade $3 / 4$ toxicity was higher if patients were treated with PF alone. During treatment with TPF, severe neutropenia (76.9 vs. $52.5 \%$ ) and alopecia (11.6 vs. $0 \%$ ) were observed more often, whereas the rate of vomiting and stomatitis was lower compared with the PF regimen. Other modified designs reached comparable results, with ORRs of up to $100 \%$ (6). In a recent meta-analysis, seven clinical trials that investigated 3-and 5-year efficacy were reviewed, and ORR was found to be better in the TPF induction chemotherapy group compared with that in the PF-based therapy group (8). In the present retrospective study, an ORR of $86 \%$ was achieved; therefore, the data are comparable with the results of already published reports.

Different to other studies, the present study also included patients treated with a palliative intent, while the majority of other studies only analyzed patients treated with a curative intent $(5,6,8,18)$. The ORR in the palliative treatment group was $75 \%$, while the group treated with a curative intent reached an ORR of $93 \%$. In contrast to investigations with potentially curable SCCHN, studies on TPF and the outcome of patients with diagnosed metastatic and recurrent SCCHN are scarce. In a previous study that included 55 patients treated in the palliative setting with $60 \mathrm{mg} / \mathrm{m}^{2}$ docetaxel, $50 \mathrm{mg} / \mathrm{m}^{2}$ cisplatin and $500 \mathrm{mg} / \mathrm{m}^{2} 5-\mathrm{FU}$, an ORR of $56 \%$ was observed (19), which is significantly lower compared with the palliative group in the present study, which achieved a ORR of $75 \%$.

Considering the survival rates, Paccagnella et al reported a 2-year survival of $61 \%$ and a median PFR of 30.4 months in the TPF group of patients treated with a curative intent (20). Compared with the published data, our data show a higher 2-year survival rate of $75 \%$ and a longer median PFR of 32 months in the entire cohort. In the TAX 324 study, better locoregional control was achieved in the TPF group (30\% failure) compared with that in the PF group $(38 \%$ failure) (5). However, the occurrence of distant metastases did not differ significantly between the two groups (5\% in the TPF and $9 \%$ in the PF group). In the present study, an incidence rate of $8 \%$ per year for locoregional failure and $4 \%$ per year for distant metastatic disease was observed.

The Karnofsky score was decreased in 8 patients $(31 \%)$ following treatment. The decrease in the Karnofsky score was particularly observed among patients with a Karnofsky score of $<70 \%$ at the beginning of treatment with docetaxel. Van Herpen et al measured the QoL using the EORTC Quality of Life Questionnaire C30 (QLQ-C30) and the EORTC QLQ Head and Neck Cancer-Specific Module (EORTC QLQ-H\&N35) (20). The standardized questionnaires and documentation of symptoms, such as prolonged cough and dysphagia, were recorded at 2, 4, 6 and 9 months following completion of therapy. In contrast to our observations made with the Karnofsky score, which is hypothesized to be correlated with the perceived QoL, QoL appeared to improve during therapy. After 6 months of therapy, the QoL in patients receiving TPF was improved compared with those receiving PF (35.1 vs. 27.2\%, respectively). Furthermore, a lower incidence of dysphagia and chronic cough and an improvement in speech were observed in the TPF cohort. A compromise in
QoL was observed in 23.6\%, which was similar to our results of the curative patient cohort.

Consistent with other clinical trials, hematological and non-hematological treatment-related side effects (particularly grade 3 and 4 leukopenia and gastrointestinal reactions) were observed in nearly all investigated patients $(5,6,8,18,19)$. Another concern is the high rate of neutropenia during chemotherapy with TPF. The TAX 323 and 324 studies reported increasing rates of neutropenia (77-83\%). Due to prophylactic treatment with GCSF in our study, the rates of neutropenia were reduced. However, these side effects were diminished after a few days of the chemotherapy and are therefore considered acceptable weighed against the survival benefit. In addition, the number and severity of non-hematological side effects such as vomiting, ototoxicity or neurotoxicity were lower than expected, whereas a higher-grade mucositis was documented.

These encouraging data must be interpreted with caution due to the relatively limited number of patients included in this study; in addition, comparing phase II and III with retrospective data may be a source of misinterpretation.

In conclusion, based on our experience with treating patients with advanced SCCHN, a combination chemotherapy with docetaxel for patients with locally advanced and recurrent or/and metastatic SCCHN appears to be advantageous when the side effects are tolerable. As regards the high toxicity rates, a careful risk-benefit-analysis for each individual patient is recommended, whereas patient compliance is crucial. A deterioration of the general condition may be expected in $31 \%$ of the patient population, particularly for patients with a Karnofsky score of $<70 \%$ at treatment initiation.

\section{References}

1. Jemal A, Bray F, Center MM, Ferlay J, Ward E and Forman D: Global cancer statistics. CA Cancer J Clin 61: 69-90, 2011.

2. Ferlay J, Shin HR, Bray F, Forman D, Mathers C and Parkin DM: Estimates of worldwide burden of cancer in 2008: GLOBOCAN 2008. Int J Cancer 127: 2893-2917, 2010.

3. Coordes A, Lenz K, Qian X, Lenarz M, Kaufmann AM and Albers AE: Meta-analysis of survival in patients with HNSCC discriminates risk depending on combined HPV and p16 status. Eur Arch Otorhinolaryngol 273: 2157-2169, 2016.

4. Tinhofer I, Jöhrens K, Keilholz U, Kaufmann A, Lehmann A, Weichert W, Stenzinger A, Stromberger C, Klinghammer K, Becker ET, et al: Contribution of human papilloma virus to the incidence of squamous cell carcinoma of the head and neck in a European population with high smoking prevalence. Eur J Cancer 51: 514-521, 2015.

5. Posner MR, Hershock DM, Blajman CR, Mickiewicz E, Winquist E, Gorbounova V, Tjulandin S, Shin DM, Cullen K, Ervin TJ, et al: Cisplatin and fluorouracil alone or with docetaxel in head and neck cancer. N Engl J Med 357: 1705-1715, 2007.

6. Vermorken JB, Remenar E, van Herpen C, Gorlia T, Mesia R, Degardin M, Stewart JS, Jelic S, Betka J, Preiss JH, et al: Cisplatin, fluorouracil, and docetaxel in unresectable head and neck cancer. N Engl J Med 357: 1695-1704, 2007.

7. Bartsch V: Assault on the mitotic spindle. The action mechanism of taxane. Pharm Unserer Zeit 34: 104-108, 2005 (In German).

8. Qian X, Ma C, Hoffmann TK, Kaufmann AM and Albers AE: Taxane-cisplatin-fluorouracil as induction chemotherapy for advanced head and neck cancer: A meta-analysis of the 5-year efficacy and safety. Springerplus 4: 208, 2015.

9. Blanchard P, Baujat B, Holostenco V, Bourredjem A, Baey C, Bourhis J and Pignon JP; MACH-CH Collaborative group: Meta-analysis of chemotherapy in head and neck cancer (MACH-NC): A comprehensive analysis by tumour site. Radiother Oncol 100: 33-40, 2011. 
10. Ma J, Liu Y, Yang X, Zhang CP, Zhang ZY and Zhong LP Induction chemotherapy in patients with resectable head and neck squamous cell carcinoma: A meta-analysis. World J Surg Oncol 11: 67, 2013.

11. Al-Mamgani A, van Rooij P, Verduijn GM, Mehilal R, Kerrebijn JD and Levendag PC: The impact of treatment modality and radiation technique on outcomes and toxicity of patients with locally advanced oropharyngeal cancer. Laryngoscope 123 : 386-393, 2013.

12. Cooper JS, Zhang Q, Pajak TF, Forastiere AA, Jacobs J, Saxman SB, Kish JA, Kim HE, Cmelak AJ, Rotman M, et al: Long-term follow-up of the RTOG 9501/intergroup phase III trial: Postoperative concurrent radiation therapy and chemotherapy in high-risk squamous cell carcinoma of the head and neck. Int J Radiat Oncol Biol Phys 84: 1198-1205, 2012.

13. Billan S, Kaidar-Person O, Atrash F, Doweck I, Haim N, Kuten A and Ronen O: Toxicity of induction chemotherapy with docetaxel, cisplatin and 5-fluorouracil for advanced head and neck cancer. Isr Med Assoc J 15: 231-235, 2013.

14. Lorch JH, Goloubeva O, Haddad RI, Cullen K, Sarlis N, Tishler R, Tan M, Fasciano J, Sammartino DE and Posner MR; TAX 324 Study Group: Induction chemotherapy with cisplatin and fluorouracil alone or in combination with docetaxel in locally advanced squamous-cell cancer of the head and neck: Long-term results of the TAX 324 randomised phase 3 trial. Lancet Oncol 12: 153-159, 2011.

15. Haddad R, O'Neill A, Rabinowits G, Tishler R, Khuri F, Adkins D, Clark J, Sarlis N, Lorch J, Beitler JJ, et al: Induction chemotherapy followed by concurrent chemoradiotherapy (sequential chemoradiotherapy) versus concurrent chemoradiotherapy alone in locally advanced head and neck cancer (PARADIGM): A randomised phase 3 trial. Lancet Oncol 14: 257-264, 2013.

16. Eisenhauer EA, Therasse P, Bogaerts J, Schwartz LH, Sargent D, Ford R, Dancey J, Arbuck S, Gwyther S, Mooney M, et al: New response evaluation criteria in solid tumours: Revised RECIST guideline (version 1.1). Eur J Cancer 45: 228-247, 2009.

17. Zhong LP, Zhang CP, Ren GX, Guo W, William WN Jr, Sun J, Zhu HG, Tu WY, Li J, Cai YL, et al: Randomized phase III trial of induction chemotherapy with docetaxel, cisplatin, and fluorouracil followed by surgery versus up-front surgery in locally advanced resectable oral squamous cell carcinoma. J Clin Oncol 31: 744-751, 2013.
18. Paccagnella A, Ghi MG, Loreggian L, Buffoli A, Koussis H, Mione CA, Bonetti A, Campostrini F, Gardani G, Ardizzoia A, et al: Concomitant chemoradiotherapy versus induction docetaxel, cisplatin and 5 fluorouracil (TPF) followed by concomitant chemoradiotherapy in locally advanced head and neck cancer: A phase II randomized study. Ann Oncol 21: 1515-1522, 2010.

19. Lin JT, Lai GM, Chang TH, Liu MT, Bi CP, Wang JW and Chen MK: Chemotherapy with modified docetaxel, cisplatin, and 5 -fluorouracil in patients with metastatic head and neck cancer. Adv Ther 29: 71-77, 2012.

20. van Herpen CM, Mauer ME, Mesia R, Degardin M, Jelic S, Coens C, Betka J, Bernier J, Remenar E, Stewart JS, et al: Short-term health-related quality of life and symptom control with docetaxel, cisplatin, 5-fluorouracil and cisplatin (TPF), 5-fluorouracil (PF) for induction in unresectable locoregionally advanced head and neck cancer patients (EORTC 24971/TAX 323). Br J Cancer 103: 1173-1181, 2010. 